\title{
"Global" and "local" predictions of dairy diet nutritional quality using near infrared reflectance spectroscopy
}

\author{
H. Tran, ${ }^{* 1}$ P. Salgado,† E. Tillard,‡ P. Dardenne,§ X. T. Nguyen, ${ }^{*}$ and P. Lecomteł \\ ${ }^{*}$ Faculty of Animal Sciences and Aquaculture, Hanoi University of Agriculture, Vietnam \\ †CIRAD, UPR Systèmes d'élevage, Montpellier, F-34398 France \\ †CIRAD, UPR Systèmes d'élevage, Saint-Pierre, La Réunion, F-97410 France \\ $\S$ Centre Wallon de Recherches Agronomiques (CRA-W), Département Qualité des Productions Agricoles, 24 Chaussée de Namur, \\ B-5030 Gembloux, Belgium
}

\section{ABSTRACT}

The objective of the study was to evaluate performance of classic (global) and innovative (local) calibration techniques to monitor cattle diet, based on fecal near infrared reflectance spectroscopy (NIRS). A 3-yr on-farm survey (2005-2008) was carried out in Vietnam and La Reunion Island to collect animal, feed intake, and feces excretion data. Feed and feces were scanned by a Foss NIRsystem 5000 monochromator (Foss, Hillerød, Denmark) to estimate diet characteristics and nutrient digestibility. A data set including 1,322 diet-fecal pairs was built and used to perform global and local calibrations. Global equations gave satisfactory accuracy [coefficient of determination $\left(\mathrm{R}^{2}\right)>0.8$, $10 \% \leq$ relative standard error of prediction (RSEP) $\leq 20 \%$ ], whereas local equations gave good accuracy $\left(\mathrm{R}^{2}>0.8, \mathrm{RSEP}<10 \%\right)$ or excellent accuracy $\left(\mathrm{R}^{2}>0.9\right.$, RSEP $<10 \%$ ) for the prediction of diet intake, quality, and digestibility. When validating the equations using the external individual data, both techniques were robust, with similar RSEP $(8 \%)$ and $\mathrm{R}^{2}(0.82)$ values. The predictive performance of global and local equations was improved ( $\mathrm{RSEP}=5 \%$ and $\mathrm{R}^{2}=$ 0.90 ) when averaged animal data from farm, visit, and similar milk production were used. In particular, local equations reduced RSEP by $43 \%$ and increased $R^{2}$ by $15 \%$, on average, compared with those obtained from individual data. The low RSEP (4\%), high $\mathrm{R}^{2}(0.96)$, and good ratio performance deviation $(\mathrm{RPD}=5)$ illustrated the excellent accuracy and robustness of the local equations. Findings suggest the ability of fecal NIRS to successfully and more accurately predict diet properties (intake, quality, and digestibility) with local calibration techniques compared with classic global techniques, especially on an averaged data set. Local calibration techniques represent an alternative promising method and potentially a decision support tool to

Received November 12, 2008.

Accepted March 25, 2010.

${ }^{1}$ Corresponding author: hiep26@yahoo.com decide whether diets meet dairy cattle requirements or need to be modified.

Key words: dairy diet, near infrared reflectance spectroscopy, quality, prediction

\section{INTRODUCTION}

Dairy performance relies on short- and medium-term management of daily amounts and quality of forages and feeds given to lactating herds. Underfeeding or overfeeding will affect animal performance, health, and environmental effects of dairy production (NRC, 2001). One kilogram difference of a concentrate such as maize at about 2.0 Mcal of $\mathrm{NE}_{\mathrm{L}} / \mathrm{kg}$ of $\mathrm{DM}$ would supply enough additional energy for over $2.5 \mathrm{~kg}$ of milk at $4 \%$ FCM. This is particularly important in early lactation, when a loss of $2 \mathrm{~L}$ of milk could result in $\geq 500 \mathrm{~L}$ being lost over the whole lactation. Monitoring the effective feed intake of animals has received much attention for many years. Fast and accurate methods are still needed to determine to what extent actual nutrient supplies match the overall requirements of dairy cattle and to help farmers with their feeding strategies.

Near infrared reflectance spectroscopy (NIRS) offers many advantages over standard methods of dietary evaluation. Near infrared reflectance spectroscopy of rumen fluid or feces can be used as a decision support tool to improve feeding management decisions (Lyons et al., 1993). An NIRS analysis of rangeland herbivore diet has been conducted with diets collected via esophageal fistula (Holechek et al., 1982) or feces (Lyons and Stuth, 1992; Lyons et al., 1995). More recently, fecal NIRS was applied to predict diet intake and diet quality of domestic animals (Awuma, 2003; Boval et al., 2004; Coleman, 2005; Landau et al., 2006; Fanchone et al., 2007, Decruyenaere et al., 2008) and wild animals (Kidane, 2005; Landau et al., 2006). However, the databases in each study were limited with regard to diet diversity and quantity of samples, and thus only permitted the development of fecal NIRS equations with global calibration from whole databases. 
The use of NIRS requires advanced multivariate calculation techniques that improve linearity and optimize precision of calibrations. There are many mathematical methods to generate the model explaining reference values from spectral data. The primary regression procedures are principal component regression and partial least squares (PLS) regression. Two broad categories of calibration techniques are global and local equations. Global equations are universal models developed from a whole sample population, whereas local equations are models developed from a group of selected samples spectrally similar to the sample to be analyzed (Gillon et al., 1999). The goal of deriving a global calibration is to maintain acceptable accuracy when covering a broad range of samples, whereas that of local calibration is to improve the accuracy of specific equations developed from similar samples of a large database (Sinnaeve et al., 1994; WinISI III software, version 1.60; Infrasoft International, State College, PA). Some authors have shown that the precision of prediction in analysis of forage quality was improved by use of a local equation (Sinnaeve et al., 1994; Chen et al., 2002). Although local calibration techniques have been used in different scientific fields over the past $15 \mathrm{yr}$, their use in animal feed science is still limited by the need for large databases to perform these techniques (Pérez-Marín et al., 2007). In fact, no study has been published on the use of these techniques for diet evaluation based on fecal spectra of dairy cattle.

In La Reunion, most dairy herds have about 30 to 60 cows, are located in upland areas, and are mainly composed of pure Holstein, with an average milk production/cow of 6,000 L/lactation. In Vietnam, almost all dairy herds are small (4 to 5 head in the northern part and 7 to 10 head in the southern part of the country), with an average milk production/cow of 4,000 L/lactation; pure Holsteins are mostly raised in mountainous areas and crossbreeds $\left(\mathrm{F}_{1}, \mathrm{~F}_{2}\right.$, and $\mathrm{F}_{3}$ from Holstein $\times$ local breed) in the lowlands. Because of the large range of dairy feeding practices among and between these regions, a large database representing extensive variations of most dairy feeding systems was created. Accordingly, innovative mathematical methods includ- ing local calibration techniques are necessary to generate accurate and precise prediction models to monitor cattle diets with this large database. The objectives of the present study were thus to develop fecal NIRS equations to predict dietary nutrient intake of dairy cattle and to compare the results of local and global equations.

\section{MATERIALS AND METHODS}

\section{Location and Dairy Systems}

The study was conducted in 2 tropical environments: La Reunion Island (France, Indian Ocean, $21^{\circ} 08^{\prime} \mathrm{S}$, $55^{\circ} 32^{\prime} \mathrm{E}$ ) and Vietnam (Southeast Asia, $10^{\circ} 0^{\prime}$ to $22^{\circ} 0^{\prime} \mathrm{N}$, $102^{\circ} 0^{\prime}$ to $\left.109^{\circ} 0^{\prime} \mathrm{E}\right)$. In La Reunion, the dairy industry is supported by the European Union and largely inspired by northern intensive ways of management. In Vietnam, dairy production is a recent farming activity, strongly promoted by the government since 2001 and carried out on a small scale. Because of the altitudinal gradients (lowlands, sea level, and mountainous areas) and land constraints, both countries have diverse temperate and tropical forage species and dairy feed resources. In each country, the herds were selected in different subregions to represent the large range of dairy feeding practices and to enlarge the variation range of the variables included in the prediction models. The herds were selected according to main feeding management practices, herd size, availability of test-day records, and the willingness of the farmer to participate in the experiment. The study was conducted from October 2005 to February 2008 in 12 and 15 dairy farms in La Reunion Island and in Vietnam, respectively. On each farm, 2 to 4 sampling periods were carried out and data on 537 and 785 dairy cows were obtained from La Reunion and Vietnam, respectively (Table 1).

\section{Feeding Systems and Diet Data Collection}

The roughage sources for dairy cattle were based on natural and cultivated fresh grasses in Vietnam $\left(\mathrm{C}_{4}\right.$ grasses: Panicum maximum, Brachiaria decumbens,

Table 1. Mean, standard deviation, and range of animal variables for model development

\begin{tabular}{|c|c|c|c|c|c|c|}
\hline \multirow[b]{2}{*}{ Variable $^{1}$} & \multicolumn{3}{|c|}{ Reunion $(\mathrm{n}=537)$} & \multicolumn{3}{|c|}{ Vietnam $(\mathrm{n}=785)$} \\
\hline & Mean & $\mathrm{SD}$ & Range & Mean & $\mathrm{SD}$ & Range \\
\hline Estimated BW (kg) & 605.97 & 61.88 & $447.10-783.74$ & 461.45 & 88.35 & $252.00-690.00$ \\
\hline NOL & 2.62 & 1.71 & $1.00-8.00$ & 3.73 & 1.70 & $1.00-11.00$ \\
\hline WOL & 25.17 & 12.20 & $1.16-91.84$ & 19.83 & 8.20 & $0.43-48.13$ \\
\hline FCM (kg) & 22.73 & 5.77 & $7.58-39.08$ & 13.36 & 5.91 & $3.05-33.65$ \\
\hline
\end{tabular}

${ }^{1} \mathrm{NOL}=$ number of lactations; WOL $=$ week of lactation. 
Table 2. Mean, standard deviation, and range of intake and diet variables for model development ${ }^{1}$

\begin{tabular}{lccccccc}
\hline & \multicolumn{3}{c}{ Reunion $(\mathrm{n}=537)$} & & \multicolumn{3}{c}{ Vietnam $(\mathrm{n}=785)$} \\
\cline { 2 - 3 } \cline { 7 - 8 } Variable & Mean & SD & Range & & Mean & SD & Range \\
\hline Diet intake & & & & & & & \\
$\quad$ DMI (kg/d) & 20.49 & 1.79 & $14.78-23.71$ & & 15.06 & 3.25 & $6.57-3.66$ \\
$\quad$ Dietary concentrate (\%) & 64.80 & 10.20 & $36.48-83.53$ & & 45.76 & 9.09 & $22.95-71.76$ \\
Diet quality & & & & & & & \\
NE (Mcal/kg of DM) & 1.42 & 0.08 & $1.26-1.72$ & & 1.31 & 0.12 & $0.97-1.55$ \\
CP (\% of DM) & 14.24 & 1.25 & $11.33-16.97$ & & 12.41 & 3.04 & $6.10-20.65$ \\
NDF (\% of DM) & 40.86 & 3.62 & $30.54-50.57$ & & 49.87 & 9.33 & $30.75-67.03$ \\
ADF (\% of DM) & 24.11 & 2.63 & $16.51-31.44$ & & 31.31 & 5.69 & $18.18-45.11$ \\
Diet digestibility & & & & & & \\
DMD (\%) & 66.51 & 3.39 & $59.70-77.76$ & & 60.78 & 5.47 & $46.27-71.11$ \\
NDFD (\%) & 50.71 & 6.31 & $35.17-69.09$ & & 47.16 & 7.24 & $22.71-61.58$ \\
ADFD (\%) & 53.08 & 6.98 & $32.54-72.81$ & & 53.74 & 6.23 & $33.78-74.81$ \\
\hline
\end{tabular}

${ }^{1}$ A total of 114 farm visits (45 in La Reunion, 69 in Vietnam) were carried out to collect data on animal, diet, and fecal spectra.

${ }^{2} \mathrm{DMD}=\mathrm{DM}$ digestibility; NDFD $=\mathrm{NDF}$ digestibility; ADFD $=$ ADF digestibility.

Brachiaria brizantha, and Pennisetum purpureum; $\mathrm{C}_{3}$ grasses: Avena sativa and Avena strigosa) or hay and grass silage in La Reunion $\left(\mathrm{C}_{4}\right.$ grasses: Chloris gayana, Sacharum, and Pennisetum clandestinum; $\mathrm{C}_{3}$ grasses: Lolium multiflorum, and Dactylis glomerata). Agricultural by-products were used throughout the year to compensate for the seasonal lack of roughage feed. Feeds mainly contained cereal grains (wheat, barley, maize), beet pulp, and rice bran as energy sources, and soybean, colza cakes, and fish meal as protein sources. The cows were housed together in freestalls partitioned to facilitate individual feeding. Each stall was equipped with 2 feed troughs and a water trough. The stalls had concrete floors and were cleaned every morning. Forages were fed ad libitum and the amount of concentrate feed was adjusted according to individual milk yield.

Dairy farms were visited 2 to 4 times during the experimental period simultaneously with milk test-day recording. During farm visits, BW was estimated using a thoracic tape $[\mathrm{BW}(\mathrm{kg})=7.445 \times$ thoracic perimeter $(\mathrm{cm})-894.084 ; \mathrm{R}^{2}=0.80 ;$ P. Hassoun and J. Y. Latchimy, CIRAD, Saint-Pierre, La Reunion Island, France; unpublished data]. Daily milk yield, milk fat contents, and DIM were obtained from the Dairy and Livestock Extension Services (Saint-Pierre, La Reunion Island, France, and Hanoi, Vietnam). For each cow, daily forage intake was estimated by using the daily amount of forages given to the group of similar yielding cows divided by the number of animals. Concentrate feed intake was assessed individually. Forage refusals were weighed the next morning. Total DMI was estimated as the difference between the total amount of feed offered and that refused, on a DM basis.

The same procedure was applied in both countries and data were collected for 1,322 lactating cows. Ani- mal performance and rations offered to these animals differed widely between countries, subregions, feeding systems, and farm scales (Tables 1 and 2). The daily milk yield varied from 7.6 to 39.1 and from 3.1 to 33.7 L, whereas daily DMI varied from 15 to 24 and from 7 to $24 \mathrm{~kg}$ of DM in La Reunion and Vietnam, respectively. The concentrate proportion in diets (DM basis) ranged from 36 to $83 \%$ and from 23 to $72 \%$, in La Reunion and Vietnam, respectively. The quality of the daily diet (Table 2) also varied widely in $\mathrm{NE}_{\mathrm{L}}$ (1.3 to 1.7 and 1.0 to $1.6 \mathrm{Mcal} / \mathrm{kg}$ of DM), CP (11.3 to $17.0 \%$ and 6.1 to $20.7 \% \mathrm{DM}$ ), NDF (30.5 to $50.6 \%$ and 30.8 to $67.0 \% \mathrm{DM}$ ), and $\mathrm{ADF}$ (16.5 to $31.4 \%$ and 18.2 to $45.1 \%$ DM) in La Reunion and Vietnam, respectively.

\section{Sampling Procedure and Chemical Calculation}

Approximately $500 \mathrm{~g}$ on a fresh matter basis of each ingredient was collected at each sampling period. Fecal samples were collected directly from the rectum in the morning. They were then dried in a forced-air oven at $70^{\circ} \mathrm{C}$ for $48 \mathrm{~h}$ to determine DM content. All dried samples were ground through a 1-mm screen (Cyclotec 1093 sample mill, Foss, Hillerød, Denmark) and stored in closed plastic boxes at room temperature before NIRS analyses.

Forage DM enzymatic digestibility and its contents of ash, $\mathrm{CP}, \mathrm{NDF}$, and ADF were predicted according to a large NIRS database and equations for tropical and temperate forages. For concentrate feed, composition and feeding value data were collected from the local suppliers. The $\mathrm{NE}_{\mathrm{L}}$ of the whole diet was calculated according to the French UFL (unite fourragere lait; forage unit for milk production) and PDI (intestinal digestive protein) equation system (INRA, 1989). The equations to calculate $\mathrm{NE}_{\mathrm{L}}$ and $\mathrm{PDI}$ were as follows: 
TRAN ET AL.

Table 3. Main statistics of equations for prediction of forage and feces composition

\begin{tabular}{|c|c|c|c|c|c|c|c|c|c|c|}
\hline \multirow[b]{3}{*}{ Constituent $^{1}$} & \multicolumn{10}{|c|}{ Statistical parameter $^{2}$} \\
\hline & \multicolumn{5}{|c|}{ Forages } & \multicolumn{5}{|c|}{ Feces } \\
\hline & $\mathrm{n}$ & Mean & $\mathrm{SD}$ & SEcv & $\mathrm{R}^{2} \mathrm{cv}$ & $\mathrm{n}$ & Mean & $\mathrm{SD}$ & SEcv & $\mathrm{R}^{2} \mathrm{cv}$ \\
\hline Ash (\% of DM) & 4,058 & 9.48 & 2.96 & 0.94 & 0.90 & 1,333 & 15.18 & 5.72 & 0.93 & 0.97 \\
\hline Protein (\% of DM) & 4,830 & 12.68 & 5.39 & 0.80 & 0.98 & 1,399 & 11.72 & 3.67 & 0.61 & 0.97 \\
\hline $\mathrm{NDF}(\%$ of DM) & 2,084 & 59.89 & 11.84 & 2.27 & 0.96 & 1,446 & 66.13 & 8.83 & 2.41 & 0.93 \\
\hline $\mathrm{ADF}(\%$ of $\mathrm{DM})$ & 2,334 & 34.73 & 6.86 & 1.54 & 0.95 & 1,444 & 36.18 & 5.73 & 1.75 & 0.91 \\
\hline $\operatorname{DMD}(\%)$ & 2,067 & 60.59 & 15.99 & 3.16 & 0.96 & & & & & \\
\hline
\end{tabular}

${ }^{1}$ Ash $=$ total mineral; DMD $=$ DM enzymatic digestibility.

${ }^{2} \mathrm{n}=$ number of samples; SEcv $=$ standard error of cross-validation; $\mathrm{R}^{2} \mathrm{cv}=$ coefficient of determination of cross-validation.

$$
\begin{gathered}
\mathrm{NE}_{\mathrm{L}}=\mathrm{GE} \times \mathrm{dE} \times(\mathrm{ME} / \mathrm{DE}) \times \mathrm{Kl}, \\
\mathrm{PDI}=\mathrm{PDIA}+\mathrm{PDIM}
\end{gathered}
$$

where GE is gross energy, $\mathrm{dE}$ is digestibility of energy, $\mathrm{ME} / \mathrm{DE}$ is the ratio of $\mathrm{ME}$ to $\mathrm{DE}, \mathrm{Kl}$ is the utilization coefficient, PDI is protein truly digested in the small intestine, PDIA is feed protein ruminally undegraded but truly digested in the small intestine, and PDIM is microbial true protein that can be synthesized from ruminally fermentable energy and nitrogen.

The chemical composition (ash, CP, NDF, and ADF) of fecal samples was predicted according to a large fecal NIRS reference database (Table 3). The amount of feces daily excreted was calculated according to the whole DM digestibility estimation of the diet: [fecal DM $=\mathrm{DMI} \times(1-\mathrm{DM}$ digestibility $)]$. The digestibilities of DM (DMD), NDF (NDFD), and ADF (ADFD) were recalculated according to feed intake/composition and feces excretion/composition.

\section{NIRS Measurements and Spectral Treatments}

All samples were scanned twice at 2-nm intervals over the 1,100 to 2,498 nm wavelengths by a Foss NIRsystem 5000 monochromator (Silver Spring, MD). The samples were scanned using closed cells, and NIR absorbance data were recorded as mean $\log 1 /$ reflectance values $(\log 1 / \mathrm{R})$. Mathematical treatment of the spectral data was performed using WinISI software (Infrasoft International; Shenk, 1992) to evaluate standardized Mahalanobis distance; samples with Mahalanobis distance $>4$ were eliminated from the spectral population. Before calibration and validation were performed, mathematical pretreatments, standard normal variate and detrend, and different derivative pretreatments were applied to spectral data. The best derivative (2.5.5.1) for each component was kept for final calibration.

\section{Model Calibration}

To develop calibration equations, diet parameters and fecal spectra were paired. In this process, individual nutrient intake and diet quality were calculated based on the determined DM intake and feed chemical composition predicted by NIRS in the previous step. A total of 1,322 diet-fecal NIRS data were paired and used to perform global and local calibrations.

Global Calibration. The calibration with full spectrum was performed using a modified PLS regression procedure with WinISI III software (Infrasoft International). To increase the accuracy while keeping the robustness of prediction, the number of elimination passes was set as minimum (1 pass).

Local Calibration. The local technique, described by Shenk et al. (1997), is a procedure that searches through a wide sample database to select samples spectrally similar to the sample to be analyzed. The subset spectra are then used to develop a specific calibration equation for predicting the unique unknown sample by using PLS regression. This process is repeated for each predicted sample. To optimize the local procedure, 3 basic factors need to be defined: the number of samples to be selected from the spectral library, the maximum number of PLS terms to be used, and the number of factors to be removed from the prediction. At the same time, other statistical factors including the mathematical pretreatment and the spectral region need to be optimized.

The local calibration in the present study was performed on the same data set using the same mathematical and spectral treatments as for global calibration. To obtain the maximum local calibration accuracy, the "batch processing" procedure in WinISI software was performed to find the best combination between the numbers of samples to be selected with the number of factors used in the modified PLS regression and the number of factors removed from predictions. A total of 
Table 4. Main statistics of independent individual data sets for validation $(\mathrm{n}=75)^{1}$

\begin{tabular}{lrcc}
\hline Variable & Mean & SD & Range \\
\hline Diet intake & & & \\
DMI (kg/d) & 17.10 & 2.78 & $11.71-23.28$ \\
Concentrate (\%) & 55.60 & 12.11 & $22.95-80.92$ \\
Diet quality & 1.40 & 0.17 & $1.17-1.72$ \\
NE (Mcal/kg of DM) & 12.86 & 2.88 & $6.13-16.38$ \\
CP (\% of DM) & 46.31 & 7.90 & $35.66-64.85$ \\
NDF (\% of DM) & 28.02 & 6.36 & $19.86-41.37$ \\
ADF (\% of DM) & & & \\
Digestibility & 64.41 & 7.76 & $53.01-77.76$ \\
DMD (\%) & 51.30 & 10.23 & $32.27-69.09$ \\
NDFD (\%) & 55.22 & 10.77 & $33.78-72.81$ \\
ADFD (\%) & &
\end{tabular}

${ }^{1}$ A total of 114 farm visits were carried out to collect data on animal, diet and fecal spectra. A total of 1,322 diet-fecal spectra were paired. Equations developed from 105 visit data $(1,247$ individual diet-fecal pairs) and the remaining 9 farm visits (75 individual diet-fecal near infrared reflectance spectroscopy pairs) were used as independent data to validate these equations.

${ }^{2} \mathrm{DMD}=\mathrm{DM}$ digestibility; NDFD $=$ NDF digestibility; ADFD = ADF digestibility

252 combinations were tested and the best combination with lowest standard error of prediction (SEP) for each calibration was then used to perform the final local calibration testing.

\section{Model Prediction}

Prediction of the Whole Individual Data Set. After performing global and local calibrations from the whole individual data set (114 visits consisting of 1,322 diet-fecal NIRS pairs), the developed equations were then used to re-predict this data set. The predicted values (output) and observed values were then analyzed to compare predictive performance of these techniques.

Prediction of the Whole Averaged Data Set. To minimize the individual effect and to mimic the farmers' practice (i.e., feeding together groups of animals having similar milk production), the whole individual data were averaged by farm, visit, and milk production level into 220 groups, and then used as another data set to test the predictive performance of global and local equations developed from the whole individual data set.

\section{Model Validation}

Validation on an Independent Individual Data Set. To build an independent validation data set, 9 farm visits consisting of 75 diet-fecal NIRS pairs of individual animals were randomly selected from the total of 114 visits (45 in La Reunion, 69 in Vietnam). The nonselected data (1,247 individual diet-fecal pairs corresponding to 105 visits) were used to develop global and local equations, whereas the selected individual data (75 individual diet-fecal pairs) were used to vali- date the accuracy and the robustness of these global and local equations. The descriptive parameters of the independent individual data set are shown in Table 4 . Calibration and validation steps are summarized in Figure 1.

Validation on an Independent Averaged Data Set. The above independent individual data set $(75$ diet-fecal pairs corresponding to 9 visits) were averaged into 16 groups. These groups were then used as another data set to validate the predictive performance of global and local equations developed from the nonselected individual data set (1,247 individual diet-fecal pairs corresponding to 105 visits).

\section{Model Evaluation}

The statistical parameters used to evaluate the predictive performance of the calibration and validation data set were standard error of calibration (SEC), SEP, relative standard error of calibration (RSEC), relative standard error of prediction $(\mathbf{R S E P}), \mathrm{R}^{2}$, and ratio performance deviation $(\mathbf{R P D})$ :

$$
\begin{gathered}
S E C, S E P=\sqrt{\frac{\sum_{i=1}^{n}\left(O_{i}-P_{i}\right)^{2}}{n}}, \\
R S E C, R S E P=\sqrt{\frac{\sum_{i=1}^{n}\left(O_{i}-P_{i}\right)^{2}}{\sum_{i=1}^{n} O_{i}^{2}}} \times 100,
\end{gathered}
$$




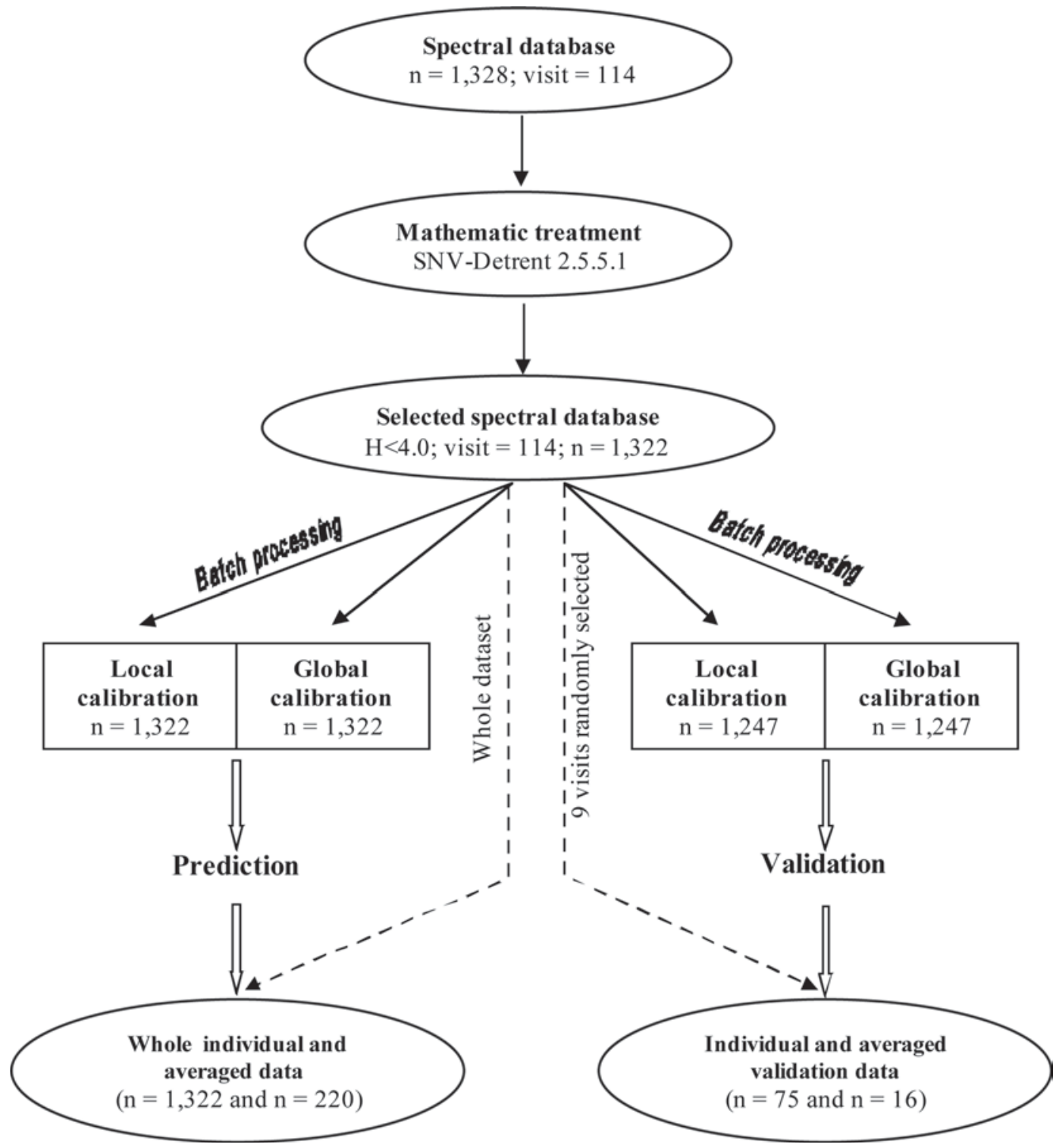

Figure 1. Diagram of global and local calibration and validation. A whole data set (1,322 diet-fecal pairs built from 114 farm visits) was used to perform global and local calibrations. To compare the predictive power of global and local equations, the whole individual and averaged data were used. To validate, 9 farm visits ( 75 individual data corresponding to 16 groups) were randomly selected to validate equations developed from the remaining 105 visit data (1,247 individual diet-fecal pairs).

$$
\begin{gathered}
R^{2}=1-\frac{S S \text { Error }}{S S \text { Total }}, \\
R P D=\frac{S D}{S E C} \text { or } \frac{S D}{S E P},
\end{gathered}
$$

where $n=$ number of pairs; $O_{i}=$ observed values of the diet component $i ; P_{i}=$ predicted values of the diet component $i$ by the calibration or validation model; $S S$ Error $=$ sum of squares of error; SS Total $=$ total variation in the model; and SD = standard deviation of the original data.

The term "accuracy" describes the bias or systematic deviation from the true value and is usually evaluated on the basis of the observed and predicted means, the $\mathrm{R}^{2}$ and RPD value. The term "precision" describes the residual error between observed and predicted values. The values of SEC and RSEC present the precision of the model. The term "robustness," in the current study, describes comparative quantitative capabilities of the prediction models when validating on an independent 
Table 5. Prediction statistics of global and local equations with the developmental data set $(\mathrm{n}=1,322)^{1}$

\begin{tabular}{|c|c|c|c|c|c|c|c|c|}
\hline \multirow[b]{3}{*}{ Variable } & \multicolumn{8}{|c|}{ Statistical parameter ${ }^{2}$} \\
\hline & \multicolumn{4}{|c|}{ Global equation } & \multicolumn{4}{|c|}{ Local equation } \\
\hline & SEC & RSEC & RPD & $\mathrm{R}^{2}$ & SEC & RSEC & $\mathrm{RPD}$ & $\mathrm{R}^{2}$ \\
\hline \multicolumn{9}{|l|}{ Diet intake } \\
\hline DMI $(\mathrm{kg} / \mathrm{d})$ & 1.53 & 8.62 & 2.50 & 0.84 & 1.37 & 7.76 & 2.80 & 0.87 \\
\hline Concentrate $(\%)$ & 5.53 & 10.07 & 2.42 & 0.83 & 5.00 & 9.07 & 2.67 & 0.86 \\
\hline \multicolumn{9}{|l|}{ Diet quality } \\
\hline $\mathrm{NE}_{\mathrm{T}}$ (Mcal $/ \mathrm{kg}$ of $\left.\mathrm{DM}\right)$ & 57.89 & 4.25 & 2.01 & 0.75 & 44.41 & 3.26 & 2.62 & 0.86 \\
\hline $\mathrm{CP}(\%$ of $\mathrm{DM})$ & 1.30 & 9.70 & 2.01 & 0.76 & 1.15 & 8.53 & 2.29 & 0.81 \\
\hline NDF ( $\%$ of DM) & 4.20 & 8.93 & 2.08 & 0.77 & 3.58 & 7.62 & 2.44 & 0.83 \\
\hline $\mathrm{ADF}(\%$ of $\mathrm{DM})$ & 2.34 & 8.22 & 2.51 & 0.84 & 2.01 & 6.94 & 2.92 & 0.88 \\
\hline \multicolumn{9}{|l|}{ Digestibility $^{3}$} \\
\hline $\operatorname{DMD}(\%)$ & 2.49 & 3.94 & 2.21 & 0.80 & 1.91 & 3.02 & 2.88 & 0.88 \\
\hline NDFD $(\%)$ & 3.33 & 6.79 & 2.13 & 0.78 & 3.02 & 6.15 & 2.35 & 0.82 \\
\hline $\operatorname{ADFD}(\%)$ & 2.65 & 4.91 & 2.47 & 0.84 & 2.08 & 3.85 & 3.15 & 0.90 \\
\hline \multicolumn{9}{|c|}{$\begin{array}{l}{ }^{1} \text { A total of } 114 \text { farm visits were carried out to collect data on animal, diet, and fecal spectra. A total of } 1,322 \\
\text { diet-fecal spectra were paired and used to develop fecal near infrared reflectance spectroscopy prediction equa- } \\
\text { tions and compared the predictive power between the global and local technique. }\end{array}$} \\
\hline
\end{tabular}

data set. In the validation step, SEP and RSEP show the robustness of the model. A prediction model was considered satisfactory if $\mathrm{R}^{2}>0.8$, and $10 \% \leq \mathrm{RSEP}$ $\leq 20 \%$, good if $\mathrm{R}^{2}>0.8$ and RSEP $<10 \%$, and excellent if $\mathrm{R}^{2}>0.9$ and RSEP $<10 \%$.

\section{RESULTS}

\section{Model Prediction}

Prediction of the Whole Individual Data Set. The predictive statistics of global and local calibration for diet intake, quality, and digestibility of the whole individual data sets are summarized in Table 5 and Figure 2. Average RSEC and $\mathrm{R}^{2}$ for all variables and for both global and local equations were about $7 \%$ and 0.82 , respectively. Local equations improved predictive capacity by increasing $\mathrm{R}^{2}$ by $7 \%$ and reducing RSEC by $14 \%$ compared with global equations.

For global calibration, the best predictive equation with lowest RSEC and highest $\mathrm{R}^{2}$ was obtained for diet constituent digestibility equations (about $5 \%$ and 0.81 , respectively). The equations to predict diet intake and diet quality also yielded low RSEC (4.25\% to $10.07 \%)$ and acceptable $\mathrm{R}^{2}$ (0.75 to 0.84 ), which illustrated the predictive performance of global calibration.

The predictive capacity for all variables was improved by local calibration compared with global calibration (reducing RSEC by $14 \%$, and increasing RPD and $\mathrm{R}^{2}$ by $19 \%$ and $6 \%$, respectively). In fact, the digestibility equations provided the lowest RSEC (about 4\%, re- duced by $17 \%$ ) and highest $\mathrm{R}^{2}$ (about 0.87 , increased by $7 \%$ ). The local calibration also improved predictive capacity of equations for diet intake and diet quality by reducing RSEC (10\% and $15 \%$, respectively) and increasing $\mathrm{R}^{2}$ (4\% and $8 \%$, respectively) compared with global calibration. In addition, these equations with RSEC and $\mathrm{R}^{2}$, which ranged from $3.02 \%$ to $9.07 \%$ and from 0.81 to 0.90 , respectively, provided a first overview of the large predictive capacity of NIRS local approach for diet evaluation.

With regard to the RPD, global and local calibrations presented high prediction performances with average values of 2.2 and 2.6, respectively. The RPD values for $\mathrm{NE}_{\mathrm{L}}, \mathrm{DMD}$, and ADFD using local calibration equations were about 30\% higher than those obtained using global calibration equations (Table 5).

Figure 2 illustrates the improvement of predictive capacity by local calibration over global calibration as the regression plot of local technique had less residual and lower difference between observed and predicted values.

Prediction of the Whole Averaged Data Set. The on-farm measurement, with animals having group access to the forage, only allowed estimates for the group. While assuming that it certainly differs between cows, the possible estimate was the average for each group with similar milk production and on similar forage feeding. These groups, well recognized by farmers, were thus averaged to reduce individual effects. The objective of the prediction with the whole averaged data set $(\mathrm{n}=220)$ was to test the prediction performance of 

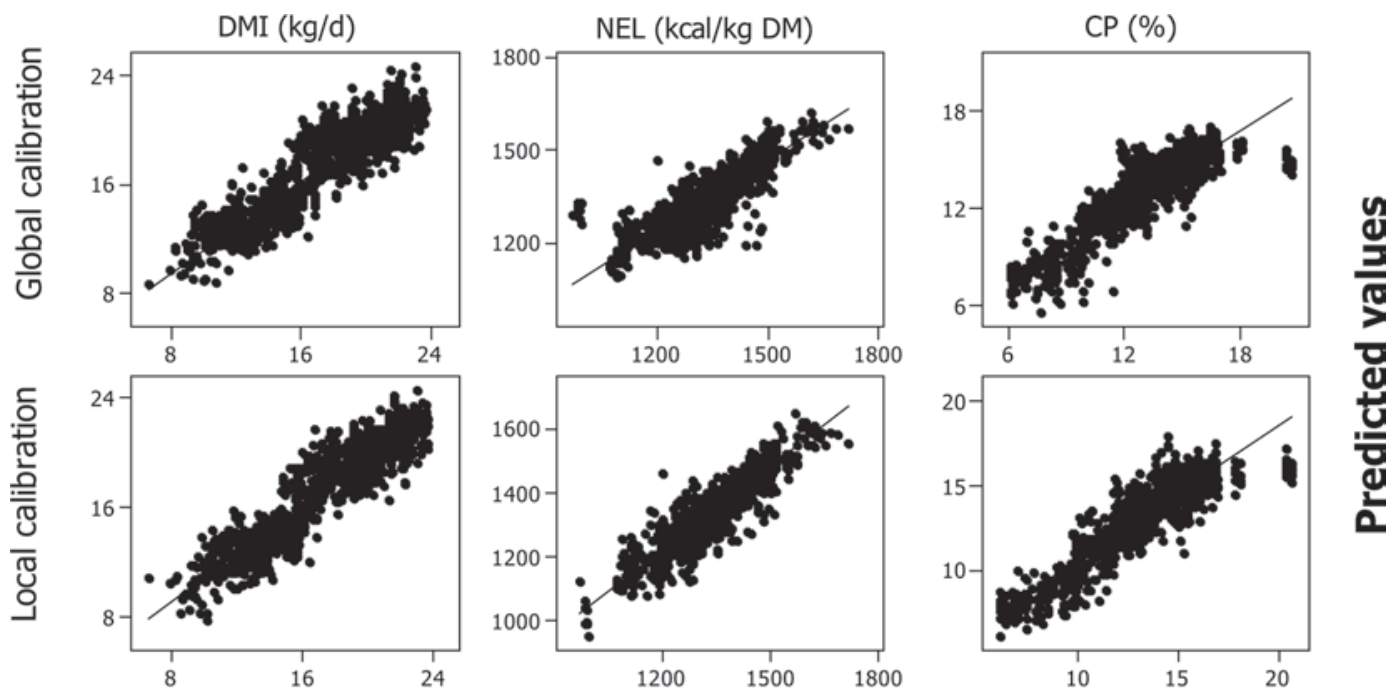

\section{Observed values}

Figure 2. Regression plots of global and local equations developed from the whole individual data set. Global and local calibrations were performed and the output (predicted values) was then compared with the observed values using scatterplot procedure (Minitab 15, 2007; Minitab, State College, PA).

the equations developed from the developmental data set $(\mathrm{n}=1,322)$ without any elimination of individual effects. The predictive statistics of global and local equations are summarized in Table 6 . Their predictive performances differed largely. Average RSEP and $\mathrm{R}^{2}$ of local equations were $44 \%$ lower and $14 \%$ higher than those from global equations, respectively. The best equations were those for diet quality $\left(\mathrm{NE}_{\mathrm{L}}, \mathrm{NDF}\right)$ and digestibility (DMD, ADFD), reducing the RSEP values by $45 \%$ to $62 \%$ and increasing the $\mathrm{R}^{2}$ values by $14 \%$ to $29 \%$, respectively. The $\mathrm{R}^{2}$ value of diet intake equations was also strongly increased by this approach (about $7 \%$ ), with an RSEP reduction of about $42 \%$. Regarding $\mathrm{RPD}$, all local equations provided high values (approxi-
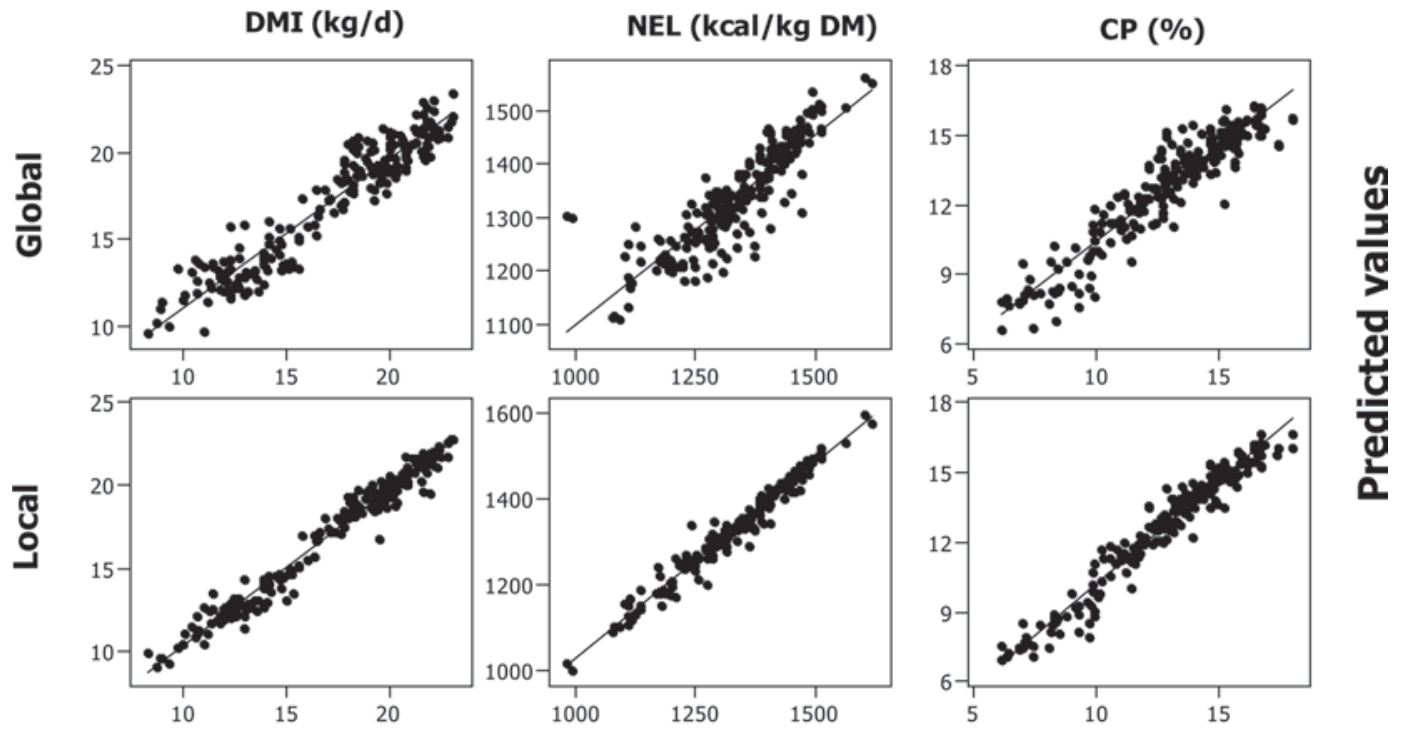

Observed values

Figure 3. Regression plot of global and local equations with the whole averaged data set. Global and local equations developed from whole individual data were tested on the whole averaged data set and the predicted values were then compared with the observed values using scatterplot procedure (Minitab 15, 2007; Minitab, State College, PA). 
Table 6. Prediction statistics of global and local equations with an averaged data set $(\mathrm{n}=220)^{1}$

\begin{tabular}{|c|c|c|c|c|c|c|c|c|}
\hline \multirow[b]{3}{*}{ Variable } & \multicolumn{8}{|c|}{ Statistical parameter ${ }^{2}$} \\
\hline & \multicolumn{4}{|c|}{ Global equation } & \multicolumn{4}{|c|}{ Local equation } \\
\hline & SEP & RSEP & $\mathrm{RPD}$ & $\mathrm{R}^{2}$ & SEP & RSEP & $\mathrm{RPD}$ & $\mathrm{R}^{2}$ \\
\hline \multicolumn{9}{|l|}{ Diet intake } \\
\hline DMI (kg/d) & 1.22 & 6.91 & 3.14 & 0.91 & 0.68 & 3.85 & 5.63 & 0.97 \\
\hline Concentrate (\%) & 4.12 & 7.74 & 3.24 & 0.89 & 2.51 & 4.72 & 5.33 & 0.96 \\
\hline \multicolumn{9}{|l|}{ Diet quality } \\
\hline $\mathrm{NE}_{\mathrm{L}}(\mathrm{Mcal} / \mathrm{kg}$ of $\mathrm{DM})$ & 55.80 & 4.18 & 2.09 & 0.75 & 21.31 & 1.60 & 5.46 & 0.97 \\
\hline $\mathrm{CP}(\%$ of $\mathrm{DM})$ & 0.96 & 7.37 & 2.74 & 0.88 & 0.64 & 4.88 & 4.11 & 0.95 \\
\hline NDF (\% of DM) & 3.74 & 7.73 & 2.34 & 0.81 & 2.05 & 4.24 & 4.27 & 0.94 \\
\hline $\mathrm{ADF}(\%$ of $\mathrm{DM})$ & 2.10 & 7.02 & 2.80 & 0.88 & 1.22 & 4.06 & 4.81 & 0.96 \\
\hline \multicolumn{9}{|l|}{ Digestibility $^{3}$} \\
\hline $\operatorname{DMD}(\%)$ & 2.37 & 3.81 & 2.32 & 0.81 & 0.91 & 1.47 & 6.05 & 0.97 \\
\hline NDFD (\%) & 3.08 & 6.32 & 2.30 & 0.79 & 2.00 & 4.12 & 3.54 & 0.91 \\
\hline $\operatorname{ADFD}(\%)$ & 2.48 & 4.66 & 2.64 & 0.85 & 1.22 & 2.29 & 5.37 & 0.97 \\
\hline
\end{tabular}

${ }^{1}$ A total of 114 farm visits consisted of 1,322 diet-fecal near infrared reflectance spectroscopy pairs. They were then averaged by farm, visit, and milk production level into 220 groups and used as another data set to test the predictive power of global and local calibration developed from the whole data set.

${ }^{2} \mathrm{SEP}=$ standard error of prediction; RSEP $=$ relative standard error of prediction $(\%)$; RPD = ratio performance deviation.

${ }^{3} \mathrm{DMD}=\mathrm{DM}$ digestibility; NDFD $=$ NDF digestibility; ADFD = ADF digestibility

mately 5), whereas global equations provided values of about 2.6. As a result, local equations improved RPD by $87 \%$. Figure 3 compares global and local fitness of the predicted and reference values in a regression plot.

Compared with statistics obtained from prediction of the whole individual data set, local equations had lower RSEP (average reduction of $44 \%$ ) and higher $\mathrm{R}^{2}$ (average increase of $14 \%$ ). With global equations, similar results were found only for DMI, concentrate proportion, and CP content.

\section{Model Validation}

Validation on an Independent Individual Data Set. Because of the different mathematical methods used for global and local calibrations, direct comparison based on predictive statistics would not be appropriate. Global calibration usually led to over- or underestimation, especially with an independent data set. For this reason, global and local equations were compared when validating with an independent individual data set $(\mathrm{n}=$ 75). Results are shown in Table 7 and Figure 4. Eightytwo percent of the variation of the independent data was explained by the models with an average RSEP of $7.8 \%$. In this step, local equations improved the predictive capacity by reducing RSEP by $8 \%$ and increasing $\mathrm{R}^{2}$ by $3 \%$.

In addition, the values of RSEP and $\mathrm{R}^{2}$ were similar between prediction and validation steps, except for intake prediction equations. The validation showed an average RSEP of $8.2 \%$ and $7.5 \%$, and an $\mathrm{R}^{2}$ of 0.80 and 0.83 for global and local equations, respectively, whereas the respective values for the calibration step were $7.6 \%$ and $6.5 \%$, and 0.80 and 0.85 . The validation showed an average RPD of 2.0 and 2.1 for global and local equations, respectively, whereas the respective values for the calibration step were 2.2 and 2.7.

Validation on an Independent Averaged Data Set. The validation statistics on the averaged data set $(\mathrm{n}=16)$ is presented in Table 8 and Figure 5. Eightysix percent of the variation of the data was explained by the models with an averaged RSEP of $7 \%$. Compared with results obtained from the independent individual data set, both global and local equations improved the predictive performance by reducing RSEP by $16 \%$ and $7 \%$ and by increasing $\mathrm{R}^{2}$ by $6 \%$ and $5 \%$, respectively. In particular, RPD was significantly increased from $24 \%$ to $36 \%$. However, the improvement of local equations over global equations was not evident for all variables, especially for digestibility equations.

\section{DISCUSSION}

\section{Predictive Performance Improvement by Local Calibration}

Since the first publications on local calibration (Shenk and Westerhaus, 1991; Shenk et al., 1997), several authors have reported on the accuracy and robustness of these predictions relative to global calibrations (Shenk and Westerhaus, 1991; Sinnaeve et al., 1994; Shenk et al., 1997; Berzaghi et al., 2000; Dambergs et al., 2006; 
$\operatorname{DMI}(\mathrm{kg} / \mathrm{d})$
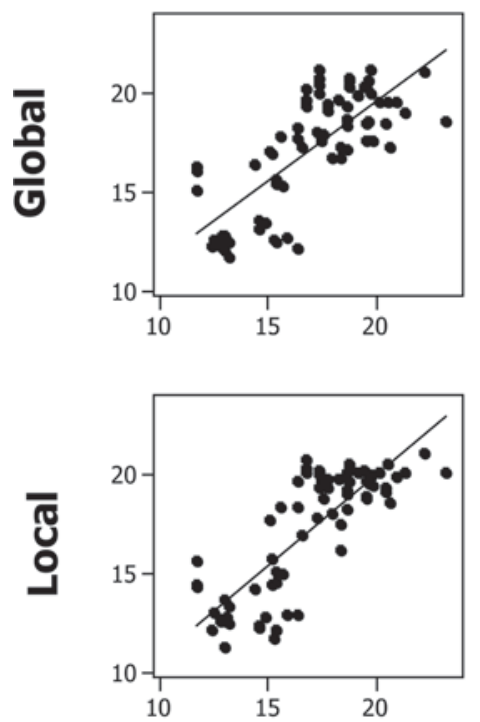

$\mathrm{CP}(\%)$
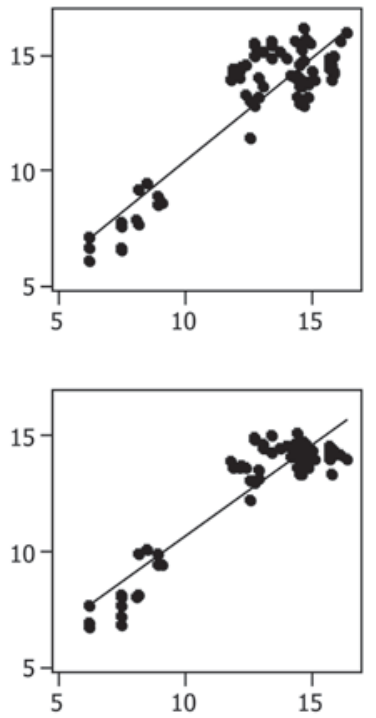

NDF (\%)
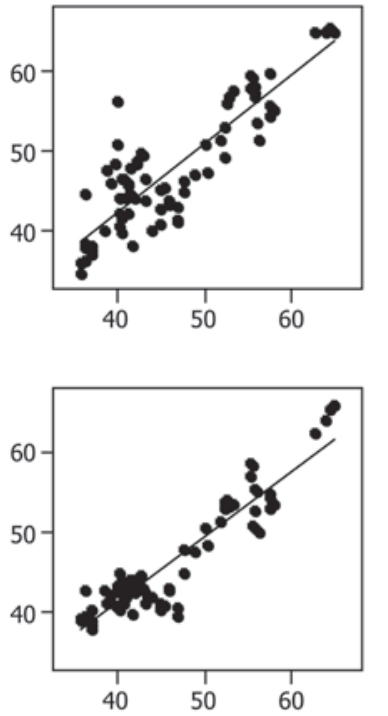

\section{Observed values}

Figure 4. Regression plot of global and local validation with the independent individual data. Global and local equations were validated and the predicted values were then compared with the observed values using scatterplot procedure (Minitab 15, 2007; Minitab, State College, PA).

Pérez-Marín et al., 2007). They found that local calibration improved the predictive capacity by 10 to $30 \%$ compared with global calibration, depending on the spectral diversity. They also reported that the major feed nutritional constituents were successfully predicted by local calibration with high accuracy, whereas some of them could not be assessed by global calibration, and finally that the larger the databases, the better the

Table 7. Validation statistics of global and local equations with an independent individual data set $(\mathrm{n}=$ $75)^{1}$

\begin{tabular}{|c|c|c|c|c|c|c|c|c|}
\hline \multirow[b]{3}{*}{ Variable } & \multicolumn{8}{|c|}{ Statistical parameter $^{2}$} \\
\hline & \multicolumn{4}{|c|}{ Global equation } & \multicolumn{4}{|c|}{ Local equation } \\
\hline & SEP & RSEP & $\mathrm{RPD}$ & $\mathrm{R}^{2}$ & SEP & RSEP & $\mathrm{RPD}$ & $\mathrm{R}^{2}$ \\
\hline \multicolumn{9}{|l|}{ Diet intake } \\
\hline DMI $(\mathrm{kg} / \mathrm{d})$ & 1.97 & 11.52 & 1.97 & 0.58 & 1.82 & 10.49 & 2.13 & 0.67 \\
\hline Concentrate (\%) & 6.16 & 11.08 & 2.18 & 0.76 & 5.85 & 10.36 & 2.30 & 0.77 \\
\hline \multicolumn{9}{|l|}{ Diet quality } \\
\hline $\mathrm{NE}_{\mathrm{L}}$ (Mcal/kg of DM) & 86.32 & 6.17 & 1.30 & 0.81 & 85.43 & 6.11 & 1.31 & 0.82 \\
\hline $\mathrm{CP}(\%$ of $\mathrm{DM})$ & 1.30 & 10.11 & 2.01 & 0.80 & 1.18 & 9.11 & 2.22 & 0.84 \\
\hline NDF ( $\%$ of DM) & 4.31 & 9.31 & 2.04 & 0.75 & 3.57 & 7.60 & 2.47 & 0.80 \\
\hline $\mathrm{ADF}(\%$ of $\mathrm{DM})$ & 2.84 & 10.14 & 2.06 & 0.81 & 2.72 & 9.44 & 2.15 & 0.82 \\
\hline \multicolumn{9}{|l|}{ Digestibility $^{3}$} \\
\hline $\operatorname{DMD}(\%)$ & 2.78 & 4.32 & 1.92 & 0.87 & 3.07 & 4.74 & 1.74 & 0.87 \\
\hline NDFD (\%) & 2.98 & 5.81 & 2.29 & 0.92 & 2.74 & 5.25 & 2.49 & 0.93 \\
\hline ADFD (\%) & 2.83 & 5.12 & 2.19 & 0.94 & 2.63 & 4.76 & 2.36 & 0.94 \\
\hline
\end{tabular}

${ }^{1} \mathrm{~A}$ total of 114 farm visits were carried out to collect data on animal, diet, and fecal spectra. A total of 1,322 diet-fecal spectra were paired. Equations developed from 105 visit data (1,247 individual diet-fecal pairs) and the remaining 9 farm visits (75 individual diet-fecal near infrared reflectance spectroscopy pairs) were used as independent data to validate these equations.

${ }^{2} \mathrm{SEP}=$ standard error of prediction; RSEP $=$ relative standard error of prediction (\%); RPD = ratio performance deviation.

${ }^{3} \mathrm{DMD}=\mathrm{DM}$ digestibility; NDFD = NDF digestibility; ADFD = ADF digestibility. 
Table 8. Validation statistics of global and local equations with an independent averaged data set $(\mathrm{n}=16)^{1}$

\begin{tabular}{|c|c|c|c|c|c|c|c|c|}
\hline \multirow[b]{3}{*}{ Variable } & \multicolumn{8}{|c|}{ Statistical parameter ${ }^{2}$} \\
\hline & \multicolumn{4}{|c|}{ Global equation } & \multicolumn{4}{|c|}{ Local equation } \\
\hline & SEP & RSEP & $\mathrm{RPD}$ & $\mathrm{R}^{2}$ & SEP & RSEP & $\mathrm{RPD}$ & $\mathrm{R}^{2}$ \\
\hline \multicolumn{9}{|l|}{ Diet intake } \\
\hline DMI $(\mathrm{kg} / \mathrm{d})$ & 1.70 & 10.32 & 1.42 & 0.68 & 1.46 & 10.34 & 1.42 & 0.78 \\
\hline Concentrate (\%) & 4.56 & 8.71 & 2.54 & 0.86 & 3.99 & 8.10 & 2.73 & 0.88 \\
\hline \multicolumn{9}{|l|}{ Diet quality } \\
\hline $\mathrm{NE}_{\mathrm{L}}($ Mcal $/ \mathrm{kg}$ of $\mathrm{DM})$ & 66.61 & 4.97 & 2.19 & 0.81 & 72.92 & 5.42 & 2.00 & 0.83 \\
\hline $\mathrm{CP}(\%$ of $\mathrm{DM})$ & 1.11 & 8.98 & 2.94 & 0.89 & 1.21 & 10.11 & 2.61 & 0.90 \\
\hline NDF (\% of DM) & 3.01 & 6.08 & 2.72 & 0.88 & 2.34 & 5.62 & 2.94 & 0.91 \\
\hline $\mathrm{ADF}(\%$ of $\mathrm{DM})$ & 2.68 & 8.63 & 2.40 & 0.82 & 2.68 & 8.64 & 2.40 & 0.85 \\
\hline \multicolumn{9}{|l|}{ Digestibility $^{3}$} \\
\hline DMD (\%) & 2.47 & 4.00 & 2.80 & 0.87 & 2.66 & 4.31 & 2.60 & 0.88 \\
\hline NDFD (\%) & 2.74 & 5.69 & 3.31 & 0.91 & 2.93 & 6.07 & 3.10 & 0.88 \\
\hline $\operatorname{ADFD}(\%)$ & 2.37 & 4.54 & 4.12 & 0.94 & 2.51 & 4.82 & 3.88 & 0.93 \\
\hline
\end{tabular}

${ }^{1} \mathrm{~A}$ total of 114 farm visits were carried out to collect data on animal, diet, and fecal spectra. A total of 1,322 diet-fecal spectra were paired. Equations developed from 105 visit data (1,247 individual diet-fecal pairs) and the remaining 9 farm visits ( 75 individual diet-fecal near infrared reflectance spectroscopy pairs) were averaged into 16 groups and used as independent data to validate these equations.

${ }^{2} \mathrm{SEP}=$ standard error of prediction; RSEP $=$ relative standard error of prediction $(\%)$; RD $=$ ratio performance deviation.

${ }^{3} \mathrm{DMD}=\mathrm{DM}$ digestibility; NDFD = NDF digestibility; ADFD = ADF digestibility

local calibration results. The large diet database used in the present study, which differed in diet composition and constituents, confirmed that the local calibration technique was more accurate than the global technique and provided excellent prediction on an averaged data set of animal groups.
In the present study, the local approach improved the RSEC and $\mathrm{R}^{2}$ of the calibration data by 10 to $23 \%$ and 10 to $30 \%$, respectively. When validated on an independent individual data set, these improvements were 1 to $18 \%$ for the RSEP and 0 to $15 \%$ for $\mathrm{R}^{2}$. This approach considerably improved prediction accuracy when the in-
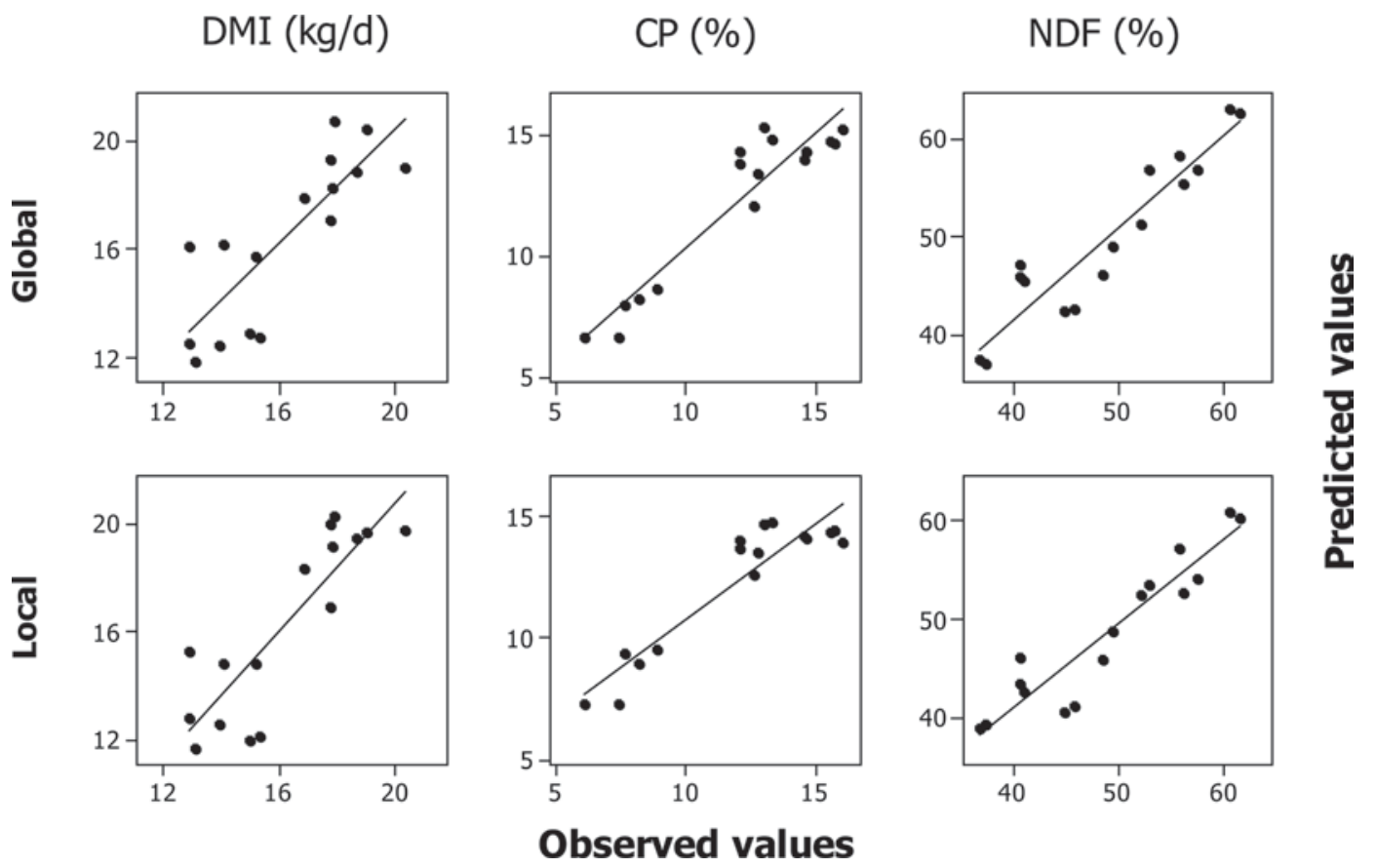

Figure 5. Regression plot of global and local validation with the independent averaged data. Global and local equations were validated and the predicted values were then compared with the observed values using scatterplot procedure (Minitab 15, 2007; Minitab, State College, PA). 
dividual effects were reduced by averaging the data and spectra among similar yielding cows. When predicting the whole averaged data set, the improvement by the local approach was 34 to $62 \%$ and 8 to $29 \%$ for RSEP and $\mathrm{R}^{2}$, respectively. However, the improvement of the local technique was small when validating on an independent averaged data set because of the low sample number $(\mathrm{n}=16)$. It is thus necessary to broaden the independent averaged data set.

The improvement of local calibration can be explained in 3 ways. First, this approach can better exploit the nonlinearity in the data by selecting samples that display a more restricted range for the parameter analyzed, for which the application of linear regression would be suitable. Second, it can exploit the nonhomogeneity of samples by using the spectral information that is similar to unknown samples to be analyzed (Sinnaeve et al., 1994). Third, predicting only one sample at a time allows optimization of the number of PLS terms in local calibration, whereas the global approach would have limited the number of terms to maintain robustness in the prediction of several samples according to the same global model. As a result, local calibration can combine the advantages of global calibration by using one database to cover a large product domain, with the acceptable accuracy with specific calibration (Berzaghi et al., 2000; Pérez-Marín et al., 2007).

Shenk et al. (1997) developed the local technique based on 2 processes: the first to set the number of PLS factors from 1 to 50 , and the second to calculate a weighted average of the predicted values generated through regression models by using various numbers of factors. The weights are then determined by the size of the regression coefficients for each PLS factor and the spectral residuals for the sample spectrum analyzed. Partial least squares models with large regression coefficients are given a low weight to avoid overfitting, and PLS models providing a poor fit to the unknown sample spectrum are given a low weight to avoid underfitting (Barton et al., 2000). Thus, local prediction is more precise and robust even though it uses more PLS terms than does global prediction. In fact, the preciseness and robustness of local calibration depend on using the proper number of PLS terms to compute specific calibration equations from samples, which are spectrally the most similar to the sample analyzed. A large database is thus needed for the calibration.

\section{Accuracy and Robustness of Local Equations}

Various statistical parameters can be used to evaluate the predictive performance of NIRS prediction, such as SEC, SEP, RSEP, RPD, and $\mathrm{R}^{2}$. To be acceptable, a prediction model must have $\mathrm{R}^{2}>0.80$, RPD $>2.5$, and SEC close to SEP (Williams, 2004; Valdés et al., 2006). The precision of a prediction model is considered good if RSEP is $<10 \%$ (Fuentes-Pila et al., 1996). At the individual level, local equations for all variables of both calibration and validation steps showed a high $\mathrm{R}^{2}(>0.80)$ and high RPD (about 2.6) and reached good preciseness, with an average RSEP $<10 \%$. The similar RSEP and $\mathrm{R}^{2}$ of both calibration and validation steps, especially in the field conditions of the present study, illustrated the robustness of local equations. At the averaged level, local equations provided excellent accuracy $\left(\mathrm{R}^{2}>0.90, \mathrm{RPD} \cong 5\right)$ with high preciseness (RSEP $<5 \%$ ) when predicting the whole averaged data set. These local equations were considered robust when validating with an independent averaged data set (average RSP $=7 \%$ and average $\mathrm{R}^{2}=0.87$ ).

Fecal NIRS appeared to be a good tool to estimate not only the quantity and quality of a diet ingested but also the a priori digestibility of constituents truly ingested. A similar efficiency of fecal NIRS has been reported using specific experimental data sets (Boval et al., 2004; Garnsworthy and Unal, 2004; Decruyenaere et al., 2008). In the present study, in contrast, data sets collected in different environments and under farmercontrolled conditions were evaluated.

Diet Intake. Some studies were successful in using fecal NIRS to predict diet intake. Boval et al. (2004) reported that the voluntary organic matter intake (OMVI) of cattle could be predicted by fecal NIRS with low SEC $\left(4.62 \mathrm{~g} / \mathrm{kg}\right.$ of $\left.\mathrm{BW}^{0.75}\right)$, equivalent to $6.4 \%$ (RSEC). Recently, Fanchone et al. (2007) and Decruyenaere et al. (2008) showed that the OMVI of ruminants was successfully predicted by fecal NIRS equations with low RSEC ( 8 to 12\%). These authors also reported that OMVI was much better when obtained by NIRS equations developed using feces rather than forage samples in the diet. Similarly, Garnsworthy and Unal (2004) reported that the direct prediction of DMI by fecal NIRS shows greater precision of prediction than indirect prediction via NIRS-predicted alkanes.

In the present study, fecal NIRS equations with the local approach provided good prediction of total DMI and concentrate proportion, with acceptable and high $\mathrm{R}^{2}$ (about 0.77 and 0.82 , respectively) and low RSEC (or RSEP; about $8 \%$ and 10\%, respectively) of both calibration and validation steps with individual data. These statistics were greatly improved when predicted with the whole averaged data. The local approach provided excellent $\mathrm{R}^{2}$ and RSEP (about 0.95 and 4\%, respectively).

To accurately predict DMI variation by fecal NIRS, the concentration of components in the feces must vary with intake levels and, consequently, the fecal spectrum must vary accordingly. According to Garnsworthy and 
Unal (2004), the fecal concentration of less digestible components increases with DMI because of increases in the rate of passage through the digestive tract. These authors also suggested that increases in DMI can dilute, although nonlinearly, the concentration of endogenous secretions in the feces. In addition, Decruyenaere et al. (2008) showed that both diet composition and intake level affect the microbial activity in the rumen because of competition between different species. It is thus expected that the residues of microbial origin in the feces would change with diet composition and intake level. These changes in fecal residues would considerably modify the NIRS spectrum.

In addition, Garnsworthy and Unal (2004) found that DMI was more accurately predicted for cows fed a mixed diet ad libitum rather than sole forage. The authors explained that the less digestible components of different ingredients in the diet could act in the same manner as dosed alkanes, being diluted as intake increases. These different indigestible components thus provide more information in feces to determine the diet intake. Relative to studies developed on experimental station data sets, in this study, a large database was built based on field conditions with extreme variations in feed components and proportions, which could also explain the good accuracy of fecal NIRS prediction equations. However, the application of fecal NIRS equation to DMI in the present study was proposed to predict averaged group data sets because the forage intake was not determined for individual animals. In farm conditions, the herd is usually divided into groups of cows according to lactation stage (beginning, mid, and end of lactation) and milk yields. Nevertheless, the difference of DMI between cows among groups could still influence the predictive capacity of prediction models. Although the present results showed improvement of prediction on the averaged data set, longitudinal monitoring of forage intake between and among groups can help to minimize bias and variation in nutrient intake and digestibility predictions.

Diet Quality. In general, fecal NIRS calibration equations identify about 8 to 12 wavelengths explaining 85 to $95 \%$ of the variation in diet quality with standard errors well within the range of those of wet chemistry analysis under controlled conditions of intake (esophageal or stall-fed tested animals; Stuth et al., 2003). Lyons and Stuth (1992) found that fecal NIRS could predict diet quality (OM digestibility, $\mathrm{CP}$ ) with equal or better accuracy than NIRS equations using forage spectra and that it had the same accuracy as chemical analysis methods. Gibbs et al. (2002) also showed that NIRS analysis of fecal samples is useful to characterize the quality of diets with different forage:concentrate ratios. In our study, based on field data, fecal NIRS for quantifying diet quality provided acceptable, good, or excellent accuracies, depending on global or local calibration and validation with different external data types. The best accuracy was found with the local validation using the averaged data of animal groups. Low SEP and excellent $\mathrm{R}^{2}$ for $\mathrm{NE}_{\mathrm{L}}$ concentration, $\mathrm{CP}$, $\mathrm{NDF}$, and ADF contents illustrated the precision and accuracy of these local equations.

Although there are no other reports on using the fecal NIRS equation to predict the ration $\mathrm{NE}_{\mathrm{L}}$, the low RSEP (about 4\%) and high $\mathrm{R}^{2}$ (about 0.84 ) of the fecal NIRS equation for $\mathrm{NE}_{\mathrm{L}}$ in the present study suggested that the prediction of $\mathrm{NE}_{\mathrm{L}}$ using fecal samples was accurate. For $\mathrm{CP}$, however, comparable results were obtained in cattle (Lyons and Stuth, 1992; Boval et al., 2004) and in goats and sheep (Leite and Stuth, 1995; Li et al., 2007). Also, the present study's local equations for NDF and ADF contents yielded SEC and $\mathrm{R}^{2}$ similar to those of Boval et al. (2004). Those authors explained that the higher precision of their fecal NIRS equations compared with that of forage NIRS equations reported by other authors were probably because of the limited range of reference values and lack of forage diversity in the diet. The very large range and variability of the developmental database in our study led to a good robustness of the equations (validated $\mathrm{R}^{2}>0.80$ ).

Diet Digestibility. The relevance of fecal NIRS to estimate diet digestibility was based on the theory that feces reflect the biological and chemical characteristics of the feed ingested, as well as the physiological status of the animal (Decruyenaere et al., 2008). Local equations for estimated diet digestibility in the present study gave $\mathrm{R}^{2}>0.80$ and appeared precise with RSEC $<7 \%$. These parameters were the most accurate and precise using the local prediction on the whole averaged data set (high $\mathrm{R}^{2}$ of about 0.96 and low RSEC of about $2 \%$ ).

Lyons et al. (1993) developed the fecal NIRS equation to estimate OM digestibility (OMD) of grass collected by free-ranging ruminants, with SEC and $\mathrm{R}^{2}$ equal to $1.66 \%$ and 0.80 , respectively. Awuma (2003) also obtained high $\mathrm{R}^{2}(0.88-0.94)$ and low RSEC (5\%) values from fecal NIRS equations to predict OMD in ruminant diets. These results are similar to the global and local calibrations and validations for DMD in the present study. Here, however, this is the a priori estimated diet digestibility; the predictive capacity of an apparent digestibility equation would have required data from experimental digestibility trials. Boval et al. (2004) reported a comparable precision of fecal NIRS equation for $\mathrm{OMD}$ in cattle $(\mathrm{RSEC}=3 \%)$. However, the $R^{2}$ value was lower than ours $(0.72)$, probably because of the limited number of samples and range for calibration (87 samples). Recently, Decruyenaere et al. 
(2008) developed a fecal NIRS equation for OMD in sheep with a high $\mathrm{R}^{2}(0.92)$ and low RSEC (3\%), which are comparable to those from our local calibration and validation with individual data but lower than those with averaged data. Although there is no published report on using the fecal NIRS equation to estimate the digestibility of dietary NDF and ADF, the calibration and validation statistics of local equations appeared good with RSEC (or RSEP) of about $6 \%$ and $4 \%$, and an $\mathrm{R}^{2}$ of 0.80 and 0.90 for NDF and ADF digestibility, respectively. However, the greater average digestibility values obtained for $\mathrm{ADF}$ compared with NDF were biologically unexpected, likely and partly because of possible errors of the ADF analytical procedures. The varying nature and structural complexities of hemicelluloses and cellulose-lignin between and within forages, concentrates, and gut-fill are likely to affect the washing capacity of the acid detergent (Van Soest, 1994; Hindrichsen et al., 2006). Such variations might have contributed to over- and underestimation of the feed and fecal true ADF contents, respectively, in the present study.

Finally, a new approach in using fecal NIRS for diet evaluation was proposed to reduce the individual effect by averaging data and fecal spectra from groups of animals with the same performance level. Through this group-based approach, the statistical parameters improved (average reduction of RSEP of $11 \%$ and average increase in $\mathrm{R}^{2}$ and $\mathrm{RPD}$ of $5 \%$ and $30 \%$, respectively) compared with those obtained from individual data sets.

\section{CONCLUSIONS}

This study demonstrated the use of NIRS for diet quality prediction under dairy farm conditions in 2 tropical regions. The very large diet database, which differed robustly in diet composition and constituents, revealed that the local technique was more accurate than the global technique. The local technique provided excellent prediction on an averaged data set of animal groups. The predictive capacity was improved with the grouped approach and is thus recommended when using fecal NIRS. We conclude that fecal NIRS can be used as a rapid and efficient tool for feed and forage quality monitoring, and diet evaluation in field conditions. In addition, the ability of fecal NIRS to predict nutrient intake during certain periods of high nutrient requirements (e.g., beginning of lactation) will potentially contribute to improved nutritional and health management of dairy herds. Extending the database to other field conditions and validating the new equations with a larger independent grouped data would strengthen decision support tools for nutrition management of dairy cattle.

\section{ACKNOWLEDGMENTS}

We thank CIRAD for financial support and the French Universitarian Agency (AUF) for Tran Hiep's PhD scholarship, the technicians of CIRAD (Pôle ELEVAGE, Saint-Pierre, La Reunion Island, France), HAU1, and NIAH (Hanoi, Vietnam) laboratories, and also Emmanuel Bourdon (University of La Reunion), Tran Hiep's supervisor, for guidance in this work financed by The La Reunion Region. The assistance of Marie-Cécile Maraval (CIRAD, Montpellier, France) with valuable suggestions about English style is greatly appreciated.

\section{REFERENCES}

Awuma, K. S. 2003. Application of NIRS fecal profiling and geostatistics to predict diet quality of African livestock. PhD Thesis. Texas A\&M Univ., College Station.

Barton, F. E., J. S. Shenk, M. O. Westerhaus, and D. B. Funk. 2000. Nonlinear regression methods in NIRS quantitative analysis. Talanta 72:28-42.

Berzaghi, P., J. S. Shenk, and M. O. Westerhaus. 2000. Local prediction with near infrared multi-product databases. J. Near Infrared Spectrosc. 8:1-9.

Boval, M., D. B. Coates, P. Lecomte, V. Decruyenaere, and H. Archimède. 2004. Faecal near infrared reflectance spectroscopy (NIRS) to assess chemical composition, in vivo digestibility and intake of tropical grass by Creole cattle. Anim. Feed Sci. Technol. 114:19-29.

Chen, M., B. Glaz, R. A. Gilbert, S. H. Daroub, F. E. Barton, and Y. Wan. 2002. Near-infrared reflectance spectroscopy analysis of phosphorus in sugarcane leaves. Agron. J. 94:1324-1331.

Coleman, W. 2005. Predicting forage intake by grazing ruminants Pages 72-90 in Ruminant Nutrition Symposium, Brooksville, Florida. http://dairy.ifas.ufl.edu/rns/2005/Coleman.pdf Accessed Mar. 15, 2009.

Dambergs, R. G., D. Cozzolino, W. U. Cynkar, L. Janik, and M. Gishen. 2006. The determination of red grape quality parameters using the LOCAL algorithm. J. Near Infrared Spectrosc. 14:71-79.

Decruyenaere, V., P. Lecomte, C. Demarquilly, J. Aufrere, P. Dardenne D. Stilmant, and A. Buldgen. 2008. Evaluation of green forage intake and digestibility in ruminants using near infrared reflectance spectroscopy (NIRS): Developing a global calibration. Anim. Feed Sci. Technol. 148:138-156.

Fanchone, A., M. Boval, P. Lecomte, and H. Archimède. 2007. Faecal indices based on near infrared spectroscopy to assess intake, in vivo digestibility and chemical composition of the herbage ingested by sheep (crude protein, fibres and lignin content). J. Near Infrared Spectrosc. 15:107-113.

Fuentes-Pila, J., M. A. DeLorenzo, D. K. Beede, C. R. Staples, and J. B. Holter. 1996. Evaluation of equations based on animal factors to predict intake of lactating Holstein cows. J. Dairy Sci. 79:1562-1571.

Garnsworthy, P. C., and Y. Unal. 2004. Estimation of dry-matter intake and digestibility in group-fed dairy cows using near infrared reflectance spectroscopy. Anim. Sci. 79:327-334.

Gibbs, S. J., D. B. Coates, D. P. Poppie, S. R. McLennan, and R. M. Dixon. 2002. The use of faecal near infra-red spectroscopy to predict dietary digestibility and crude protein content for cattle fed supplements. Direct and indirect means of predicting forage quality through near infrared reflectance spectroscopy. Field Crops Res. 84:45-56. 
Gillon, D., C. Houssard, and R. Joffre. 1999. Using near-infrared reflectance spectroscopy to predict carbon, nitrogen and phosphorous content in heterogeneous plant material. Oecologia 8:173-182.

Hindrichsen, I. K., M. Kreuzer, J. Madsen, and K. E. Bach Knudsen. 2006. Fiber and lignin analysis in concentrate, forage, and feces: Detergent versus enzymatic-chemical method. J. Dairy Sci. $89: 2168-2176$.

Holechek, J. L., J. S. Shenk, M. Vanvra, and D. Arthun. 1982. Prediction of forage quality using near infrared reflectance spectroscopy on esophageal fistula samples from cattle on mountain range. J. Anim. Sci. 55:971-975.

INRA. 1989. Ruminant nutrition. Recommended allowances and feed tables. Institut National de la Recherche Agronomique (INRA), John Libbey Eurotext, Montrouge, France.

Kidane, N. F. 2005. Fecal near-infrared reflectance spectroscopy calibration for predicting diet quality and intake of donkeys. PhD Thesis. Texas A\&M Univ., College Station.

Landau, S., T. Glasser, and L. Dvash. 2006. Monitoring nutrition in small ruminants by aids of near infrared reflectance spectroscopy (NIRS) technology: A review. Small Rumin. Res. 61:1-11.

Leite, E. R., and J. W. Stuth. 1995. Fecal NIRS equations to assess diet quality of free-ranging goats. Small Rumin. Res. 15:223-230.

Li, H., D. Tolleson, J. Stuth, K. Bai, F. Mo, and S. Kronberg. 2007. Faecal near infrared reflectance spectroscopy to predict diet quality for sheep. Small Rumin. Res. 68:263-268.

Lyons, R. K., and J. W. Stuth. 1992. Fecal NIRS equations for predicting diet quality of free-ranging cattle. J. Range Manage. 45:230-244

Lyons, R. K., J. W. Stuth, and J. P. Angerer. 1995. Technical note: Fecal NIRS equation field validation. J. Range Manage. 48:380382 .

Lyons, R. K., J. W. Stuth, J. E. Huston, and J. P. Angerer. 1993. Predictions of the nutrient composition of the diets of supplemented versus unsupplemented grazing beef cows based on near-infrared reflectance spectroscopy of feces. J. Anim. Sci. 71:530-538.
NRC. 2001. Nutrient Requirements of Dairy Cattle. 7th rev. ed. National Academy Press, Washington, DC.

Pérez-Marín, D., A. Garrido-Varo, and J. E. Guerrero. 2007. Nonlinear regression methods in NIRS quantitative analysis. Talanta $72: 28-42$.

Shenk, J. S. 1992. NIRS analysis of natural agricultural products. Pages 235-240 in Near Infrared Spectroscopy. Bridging the Gap Between Data Analysis and NIR Applications. Ellis Horwood, Chichester, UK.

Shenk, J. S., and M. O. Westerhaus. 1991. New standardization and calibration procedures for near infrared spectroscopy analytical systems. Crop Sci. 31:1694-1696.

Shenk, J. S., M. O. Westerhaus, and P. Berzaghi. 1997. Investigation of a local calibration procedure for near infrared instruments. J. Near Infrared Spectrosc. 5:223-232.

Sinnaeve, G., P. Dardenene, and R. Agnenssenes. 1994. Global or local? A choice of NIR calibration in analyses of forage quality. J Near Infrared Spectrosc. 2:163-175.

Stuth, J., A. Jama, and D. Tolleson. 2003. Direct and indirect means of predicting forage quality through near infrared reflectance spectroscopy. Field Crops Res. 84:45-56.

Valdés, C., S. Andrés, F. J. Giráldez, R. García, and A. Calleja. 2006. Potential use of visible and near infrared reflectance spectroscopy for the estimation of nitrogen fractions in forages harvested from permanent meadows. J. Sci. Food Agric. 86:308-314.

Van Soest, P. J. 1994. Nutritional Ecology of the Ruminant. 2nd ed. Cornell University Press, Ithaca, NY.

Williams, P. 2004. Near-infrared technology, getting the best out of light. A short course in the practical implementation of near-infrared spectroscopy for the user. Edition 2.0. PDK Grain, PDK Projects, Inc., Nanaimo, British Colombia, and Winnipeg, Manitoba, Canada. 